\title{
Stark broadening and atomic data for Ar XVI
}

\author{
R. Aloui ${ }^{1}, \mathbf{H}$. Elabidi ${ }^{2,3}$ and S. Sahal-Bréchot ${ }^{4}$ \\ ${ }^{1}$ Labortoire de Spectroscopie et Dynamique Moléculaire, LSDM, École \\ Nationale Supérieure d'ingénieurs de Tunis, University of Tunis, Tunisia \\ (E-mail: rihabaloui88@gmail.com) \\ 2 Department of Physics, Deanship of the Foundation Year, Umm Al-Qura \\ University, Makkah Almukarramah, Saudi Arabia \\ ${ }^{3}$ Groupe de Recherche en Physique Atomique et Astrophysique, LSDM, \\ Faculté des Sciences de Bizerte, Université de Carthage, Tunisia \\ 4 Sorbonne Université, Observatoire de Paris, Université PSL, CNRS, \\ LERMA, F-92190 Meudon, France
}

Received: August 1, 2019; Accepted: August 16, 2019

\begin{abstract}
Stark broadening and atomic data calculations have been developed for the recent years, especially atomic and line broadening data for highly ionized ions of argon. We present in this paper atomic data (such as energy levels, line strengths, oscillator strengths and radiative decay rates) for Ar XVI ion and quantum Stark broadening calculations for 10 Ar XVI lines. Radiative atomic data for this ion have been calculated using the University College London (UCL) codes (SUPERSTRUCTURE, DISTORTED WAVE, JAJOM) and have been compared with other results. Using our quantum mechanical method, our Stark broadening calculations for Ar XVI lines are performed at electron density $N_{e}=10^{20} \mathrm{~cm}^{-3}$ and for electron temperature varying from $7.5 \times 10^{5}$ to $7.5 \times 10^{6} \mathrm{~K}$. No Stark broadening results in the literature to compare with. So, our results come to fill this lack of data.
\end{abstract}

Key words: line:profiles- stars- atomic data- Stark line broadening.

\section{Introduction}

Lithium-like ions are of importance in astrophysical and magnetized plasmas. Many emission lines of highly ionized argon, such as Ar IX-XVIII, were studied in Dere et al. (2001). Many Li-like transitions were useful for the determination of chemical abundances (Lemen et al., 1986). The number of the previous publications shows the importance of the Li-like ions: In Aggarwal \& Keenan (2013), the authors reported the atomic data for Li-like ions with $12 \leq Z \leq 20$. In Whiteford et al. (2002), the authors performed the calculations of energy levels for Ar XVI ion by using AUTOSTRUCTURE (AS) code of Badnell (1997). Recently, in McKeown et al. (2004), the authors calculated the energy levels and radiative rates for Ar XVI and Fe XXIV. Atomic and line broadening data of highly ionized atoms are required in plasma physics. These parameters are used in the opacity calculations. They were also required for the modelling of fusion 
plasmas (Peacock et al., 1997) as many elements were presented as impurities in the reactor walls. They determined the chemical abundances of elements and they used to test various theoretical approximations (Dimitrijević, 2003). Theoretical atomic data for Ar XVI were required for the modelling and diagnostics of plasmas and not available from measurements (McKeown et al., 2004).

Argon ions played a great role in technological devices and plasma applications (Djurović et al., 2011). We choose to study Ar XVI because of its ground configuration $1 \mathrm{~s}^{2} 2 \mathrm{~s}^{1}$ (with one external electron on closed shells), this ion is like hydrogen, thus their atomic properties can be calculated $a b$ initio with a great accuracy. Therefore we perform another calculations to assess a precision of the available data, and that results can be applied with confidence in plasma diagnostics. Despite the importance of these parameters for stellar plasma research, for the interpretation of high-resolution spectra from astrophysical sources, the line broadening data of Ar XVI are totally missing in the literature. To fill this lack, we calculated their parameters using our quantum mechanical method. We hope that our results enrich the databases of astrophysicists. In the present work, the calculations of atomic data are computed by the sequence of UCL (University College, London) atomic packages (SUPERSTRUCTURE (Eissner et al., 1974)/DW (Eissner, 1998)/JAJOM (Saraph, 1978)). In Elabidi et al. (2014); Elabidi \& Sahal-Bréchot (2018); Aloui et al. (2018, 2019), the authors adapted these packages to provide Stark broadening data for several argon lines missing in the literature. This method gave acceptable results. In Aloui et al. (2018), we calculated the Stark widths for Ar VII spectral lines. In Aloui et al. (2019), we computed quantum Stark broadening data for Ar VIII and Ar IX lines.

\section{Outline of our line broadening method}

To perform the present line broadening calculations, we have used our quantum mechanical method obtained in Elabidi et al. (2004, 2008). The expression of the full width at half-maximum (valid at temperatures and densities studied here), $W$ is given by the following expression:

$$
\begin{aligned}
W= & 2 N\left(\frac{\hbar}{m}\right)^{2}\left(\frac{2 m \pi}{k_{B} T}\right)^{\frac{1}{2}} \\
& \times \int_{0}^{\infty} \Gamma_{w}(E) \exp \left(-\frac{\epsilon}{k_{B} T}\right) d\left(\frac{\epsilon}{k_{B} T}\right),
\end{aligned}
$$

where the integration is over the Maxwellian velocity distribution, $m$ is the electron mass, $k_{B}$ is the Boltzmann constant, $N$ is the electron density, $T$ denotes 
the electron temperature, $\epsilon$ is the incident electron energy, and

$$
\begin{aligned}
\Gamma_{w}(\epsilon)= & \sum_{J_{i}^{T}} \frac{\left[K_{f}^{T}, K_{f}, J_{i}^{T}, J_{f}^{T}\right]}{2} \\
& \times\left\{\begin{array}{c}
J_{i} K_{i} l \\
K_{f} J_{f} 1
\end{array}\right\}^{2}\left\{\begin{array}{l}
K_{i} J_{i}^{T} s \\
J_{f}^{T} K_{f} 1
\end{array}\right\}^{2} \\
& \times\left[1-\left(\operatorname{Re}\left(\mathbf{S}_{i}\right) \operatorname{Re}\left(\mathbf{S}_{f}\right)+\operatorname{Im}\left(\mathbf{S}_{i}\right) \operatorname{Im}\left(\mathbf{S}_{f}\right)\right)\right]
\end{aligned}
$$

where $L_{i}+S_{i}=J_{i}, J_{i}+l=K_{i}$ and $K_{i}+s=J_{i}^{T} . L$ is the atomic orbital angular momentum, $S$ is the spin of the target, $l$ is the electron orbital momentum. The superscript $T$ designates the operators of the total system (electron+ion). $\mathbf{S}_{i}\left(\mathbf{S}_{f}\right)$ represent the scattering matrix elements for the initial (final) levels in intermediate coupling. $\operatorname{Re}(\mathbf{S})$ and $\operatorname{Im}(\mathbf{S})$ denotes the real and the imaginary parts of the $\mathbf{S}$-matrix, respectively. $\left\{\begin{array}{l}a b c \\ d e f\end{array}\right\}$ designate $6-\mathrm{j}$ symbols and we use the notation $[x, y, \ldots]=(2 x+1)(2 y+1) \ldots$

To calculate both $\mathbf{S}_{i}$ and $\mathbf{S}_{f}$, we use the same incident electron energy $\epsilon=$ $m v^{2} / 2$. The SUPERSTRUCTURE (SST) code (Eissner et al., 1974) calculates the atomic structure in intermediate coupling, where configuration interaction and relativistic corrections (spin-orbit, mass, Darwin and one-body) are included according the Breit-Pauli approach (Bethe \& Salpeter, 1957). The radial wave functions are determined by diagonalization of the non relativistic Hamiltonian using orbitals calculated in a scaled Thomas FermiDirac Amaldi (TFDA) potential. The potential depends on scaling parameters $\lambda_{l}$ that have been obtained by a selfconsistent energy minimization on the term energies included in our calculations. The DISTORTED WAVE (DW) code (Eissner, 1998) performs the electron-ion scattering calculations and produces reaction matrices $\mathbf{R}$ in $L S$ coupling. The JAJOM code (Saraph, 1978) treats the scattering calculations in intermediate coupling. This code uses the term coupling coefficients (TCC) -resulting of SST calculations- and these matrices in $L S$ coupling (obtained by DW) to calculate collision strengths and reactance matrices $\mathbf{R}$ in intermediate coupling. This resulting matrices $\mathbf{R}$ and the $\operatorname{Re} \mathbf{S}(\operatorname{Im} \mathbf{S})$ which are obtained using JAJPOLARI program -the transformed of JAJOM code- (Elabidi \& Dubau, unpublished results) and RtoS program (Dubau, unpublished results) have been used as input data suitable for the formula (2). Re $\mathbf{S}$ and $\operatorname{Im} \mathbf{S}$ are assessed by the expressions below:

$$
\operatorname{Re} \mathbf{S}=\left(1-\mathbf{R}^{2}\right)\left(1+\mathbf{R}^{2}\right)^{-1}, \operatorname{Im} \mathbf{S}=2 \mathbf{R}\left(1+\mathbf{R}^{2}\right)^{-1}
$$




\section{Results and discussions}

\subsection{Structure and radiative data}

Structural and radiative atomic data have been calculated using the SUPERSTRUCTURE code of Eissner et al. (1974). We have used 6 configurations: $1 \mathrm{~s}^{2}$ $(2 \mathrm{~s}, 2 \mathrm{p}, 3 \mathrm{~s}, 3 \mathrm{p}, 3 \mathrm{~d}$ and $4 \mathrm{~s})$. These configurations give rise to 6 terms and 9 levels of fine structure. The code (SST) provides also the scaling parameters $\left(\lambda_{s}=1.3116, \lambda_{p}=0.9392\right.$ and $\left.\lambda_{d}=0.8683\right)$. In Table 1 , we display the present energy levels for Ar XVI in $\mathrm{cm}^{-1}$ and compare them with the experimental results of NIST (Kramida et al., 2018), with those calculated in McKeown et al. (2004) (GRASP) who used the GRASP (General purpose Relativistic Atomic Structure Package) code (Dyall et al., 1989), with those calculated from McKeown et al. (2004) (CIV3) who used the CIV3 code of Hibbert (1975), and with those from Whiteford et al. (2002) (AS) who used the AUTOSTRUCUTRE code (Badnell, 1997). As it is shown in Table 1, the average errors between our results and all the other ones are less than $1 \%$.

The absorption oscillator strengths $f_{i j}$ and radiative rates $A_{j i}$ (in s ${ }^{-1}$ ) for a transition $i \rightarrow j$ are related by the following expression (Aggarwal \& Keenan, 2013):

$$
f_{i j}=\frac{m c}{8 \pi^{2} e^{2}} \lambda_{j i}^{2} \frac{\omega_{j}}{\omega_{i}} A_{j i}=1.49 \times 10^{-16} \lambda_{j i}^{2} \frac{\omega_{j}}{\omega_{i}} A_{j i}
$$

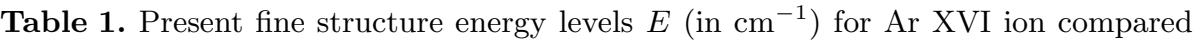
with NIST values (Kramida et al., 2018), with GRASP values: the calculated results from McKeown et al. (2004) who used the GRASP code of Dyall et al. (1989), with CIV3 values: the results from McKeown et al. (2004) who used the CIV3 code from Hibbert (1975), and with AS values: the results obtained by Whiteford et al. (2002) who used the AS code (Badnell, 1997).

\begin{tabular}{ccccccc}
\hline \hline$k$ & Level & $E$ & NIST & GRASP & CIV3 & AS \\
\hline 1 & $2 \mathrm{~s}^{2} \mathrm{~S}_{1 / 2}$ & 0.0 & 0.0 & 0.0 & 0.0 & 0.0 \\
2 & $2 \mathrm{p}{ }^{2} \mathrm{P}^{\circ}{ }_{1 / 2}$ & 258659. & 257026. & 258563.03 & 259759.16 & 257860.71 \\
3 & $2 \mathrm{p}{ }^{2} \mathrm{P}^{\circ} 3 / 2$ & 283924. & 282603. & 285218.22 & 284263.50 & 283275.87 \\
4 & $3 \mathrm{~s}{ }^{2} \mathrm{~S}_{1 / 2}$ & 4176900. & 4176030. & 4176030. & 4177350. & 4179640. \\
5 & $3 \mathrm{p}{ }^{2} \mathrm{P}^{\circ} 1 / 2$ & 4248504. & 4246950. & 4247060. & 4248110. & 4250730. \\
6 & $3 \mathrm{p}{ }^{2} \mathrm{P}^{\circ}{ }_{3 / 2}$ & 4255873. & 4254180. & 4255150. & 4255370. & 4258250. \\
7 & $3 \mathrm{~d}{ }^{2} \mathrm{D}_{3 / 2}$ & 4283042. & 4281030. & 4281730. & 4282300. & 4285880. \\
8 & $3 \mathrm{~d}^{2} \mathrm{D}_{5 / 2}$ & 4285399. & 4283560. & 4284110. & 4284660. & 4288250. \\
9 & $4 \mathrm{~s}^{2} \mathrm{~S}_{1 / 2}$ & 5606962. & 5605700. & 5605740. & 5607210. & 5610400.
\end{tabular}


where $m$ and $e$ are the electron mass and charge, respectively, $c$ is the velocity of light, $\lambda_{j i}$ is the transition wavelength in $\AA$, and $\omega_{i}$ and $\omega_{j}$ are the statistical weights of the lower $(i)$ and upper $(j)$ levels, respectively. Similarly, the oscillator strengths $f_{i j}$ (dimensionless) and the line strength $S$ (in atomic units, 1 a.u. $=$ $6.460 \times 10^{-36} \mathrm{~cm}^{2} \mathrm{esu}^{2}$ ) are related by the following standard equations for the electric dipole (E1) transitions:

$$
A_{j i}=\frac{2.0261 \times 10^{18}}{\omega_{j} \lambda_{j i}^{3}} S^{E 1} \text { and } f_{j i}=\frac{303.75}{\omega_{i} \lambda_{j i}} S^{E 1}
$$

Table 2 displays present radiative decay rates $A_{j i}\left(\right.$ in $\left.\mathrm{s}^{-1}\right)$ for Ar XVI transitions which are compared with GRASP and CIV3 results from McKeown et al. (2004), and with AS results from Whiteford et al. (2002). The difference between our results and these references (McKeown et al., 2004; Whiteford et al., 2002 ) varies from nearly $0 \%$ to $19 \%$. The maximum error for radiative decay rates in CIV3 results $\left(\Delta_{\mathrm{CIV} 3}\right.$ is about $\left.19 \%\right)$ in the transition $4 \mathrm{~s}^{2} \mathrm{~S}_{1 / 2}-2 \mathrm{p}{ }^{2} \mathrm{P}^{\circ}{ }_{1 / 2}$ $(9-2)$. But the average value of errors still acceptable, is about $4 \%$. According to this comparison we note that our $A_{j i}$ values are relatively close to the other

Table 2. Present radiative decay rates: $A_{i j}$ (in $\mathrm{s}^{-1}$ ), compared with GRASP values: the results from McKeown et al. (2004) who used the GRASP code of Dyall et al. (1989), with CIV3 values: the results from McKeown et al. (2004) who used the CIV3 code of Hibbert (1975), and with AS values: the results from Whiteford et al. (2002) who used the AS code of Badnell (1997) for Ar XVI transitions. $i$ and $j$ are labelling the levels as in Table 1.

\begin{tabular}{cccccccc}
\hline \hline$i-j$ & $A_{i j}$ & GRASP & CIV3 & AS & $\Delta_{\text {GRASP }}$ & $\Delta_{\text {CIV3 }}$ & $\Delta_{\text {AS }}$ \\
\hline $2-1$ & $1.179 \mathrm{E}+09$ & $1.166 \mathrm{E}+09$ & $1.195 \mathrm{E}+09$ & $1.170 \mathrm{E}+09$ & 1.10 & 1.36 & 0.76 \\
$3-1$ & $1.564 \mathrm{E}+09$ & $1.552 \mathrm{E}+09$ & $1.573 \mathrm{E}+09$ & $1.540 \mathrm{E}+09$ & 0.77 & 0.58 & 1.53 \\
$4-2$ & $1.836 \mathrm{E}+11$ & $2.012 \mathrm{E}+11$ & $1.880 \mathrm{E}+11$ & $1.970 \mathrm{E}+11$ & 9.59 & 2.40 & 7.30 \\
$4-3$ & $3.879 \mathrm{E}+11$ & $4.097 \mathrm{E}+11$ & $3.900 \mathrm{E}+11$ & $3.860 \mathrm{E}+11$ & 5.62 & 0.54 & 0.49 \\
$5-1$ & $1.433 \mathrm{E}+12$ & $1.449 \mathrm{E}+12$ & $1.440 \mathrm{E}+12$ & $1.420 \mathrm{E}+12$ & 1.12 & 0.49 & 0.91 \\
$5-4$ & $1.530 \mathrm{E}+08$ & $1.494 \mathrm{E}+08$ & $1.468 \mathrm{E}+08$ & $1.490 \mathrm{E}+08$ & 2.35 & 4.05 & 2.61 \\
$6-1$ & $1.423 \mathrm{E}+12$ & $1.424 \mathrm{E}+12$ & $1.425 \mathrm{E}+12$ & $1.430 \mathrm{E}+12$ & 0.07 & 0.14 & 0.49 \\
$6-4$ & $2.051 \mathrm{E}+08$ & $2.042 \mathrm{E}+08$ & $1.974 \mathrm{E}+08$ & $2.020 \mathrm{E}+08$ & 0.44 & 3.75 & 1.51 \\
$7-2$ & $3.619 \mathrm{E}+12$ & $3.639 \mathrm{E}+12$ & $3.630 \mathrm{E}+12$ & $3.670 \mathrm{E}+12$ & 0.55 & 0.30 & 1.41 \\
$7-3$ & $7.203 \mathrm{E}+11$ & $7.229 \mathrm{E}+11$ & $7.219 \mathrm{E}+11$ & $7.190 \mathrm{E}+11$ & 0.36 & 0.22 & 0.18 \\
$7-5$ & $1.111 \mathrm{E}+07$ & $1.052 \mathrm{E}+07$ & $1.073 \mathrm{E}+07$ & $1.160 \mathrm{E}+07$ & 5.31 & 3.42 & 4.41 \\
$7-6$ & $1.079 \mathrm{E}+06$ & $9.733 \mathrm{E}+05$ & $1.047 \mathrm{E}+06$ & $1.130 \mathrm{E}+06$ & 9.80 & 2.97 & 4.73 \\
$8-3$ & $4.330 \mathrm{E}+12$ & $4.338 \mathrm{E}+12$ & $4.335 \mathrm{E}+12$ & $4.320 \mathrm{E}+12$ & 0.18 & 0.12 & 0.23 \\
$8-6$ & $8.308 \mathrm{E}+06$ & $7.580 \mathrm{E}+06$ & $8.088 \mathrm{E}+06$ & $8.680 \mathrm{E}+06$ & 8.76 & 2.65 & 4.48 \\
$9-2$ & $8.715 \mathrm{E}+10$ & $9.192 \mathrm{E}+10$ & $7.044 \mathrm{E}+10$ & $7.550 \mathrm{E}+10$ & 5.47 & 19.17 & 13.37 \\
$9-3$ & $1.649 \mathrm{E}+11$ & $1.846 \mathrm{E}+11$ & $1.514 \mathrm{E}+11$ & $1.490 \mathrm{E}+11$ & 11.95 & 8.19 & 9.64 \\
$9-5$ & $5.693 \mathrm{E}+10$ & $5.270 \mathrm{E}+10$ & $5.268 \mathrm{E}+10$ & $5.410 \mathrm{E}+10$ & 7.43 & 7.47 & 4.97 \\
$9-6$ & $1.121 \mathrm{E}+11$ & $1.074 \mathrm{E}+11$ & $1.086 \mathrm{E}+11$ & $1.060 \mathrm{E}+11$ & 4.19 & 3.12 & 5.44 \\
& & & & & & & \\
\hline \hline
\end{tabular}


ones (GRASP, CIV3, AS). Present absorption oscillator strengths $f_{i j}(i \rightarrow j)$ and our line strengths $S$ for Ar XVI transitions are reported in Table 3 and compared with GRASP results from McKeown et al. (2004). The percentage errors between the present two parameters $\left(S\right.$ and $\left.f_{i j}\right)$ and GRASP results vary from nearly $0 \%$ to $12 \%$, for the both parameters. We found the maximum error in $4 \mathrm{~s}^{2} \mathrm{~S}_{1 / 2}-2 \mathrm{p}^{2} \mathrm{P}_{3 / 2}^{\circ}(9-3)$ transition nearly to $12 \%$. Also the average value of errors still acceptable, is about $3 \%$.

\subsection{Line broadening results}

We perform the calculations of Stark broadening for 10 Ar XVI lines. Quantum results $W$ are calculated using our expression (1) and using 6 configurations. We use a range of electron temperature form $7.5 \times 10^{5}$ to $7.5 \times 10^{6} \mathrm{~K}$ and at electron density $N_{e}=10^{20} \mathrm{~cm}^{-3}$. Present calculations are reported in Table 4 . We can prove that with the electron temperature and density values chosen in the present work, the condition of the impact approximation is valid: this approximation means that the duration $\tau$ of an interaction must be much smaller than the mean interval between two collision $\Delta T$ (Baranger, 1958):

$\tau \ll \Delta T . \tau$ can be expressed as $\tau \approx \frac{\rho_{t y p}}{v_{t y p}}$, where $\rho_{t y p}$ is a typical impact parameter, and $v_{t y p}$ presents a mean typical velocity. $\Delta T$ is of the order of the

Table 3. Present line strengths $S$ and absorption oscillator strengths $f_{i j}$ are compared with GRASP values: the results from McKeown et al. (2004) who used the GRASP code of Dyall et al. (1989) for Ar XVI transitions.

\begin{tabular}{|c|c|c|c|c|c|c|}
\hline \multirow{2}{*}{$\begin{array}{c}\text { Levels } \\
i-j\end{array}$} & \multicolumn{3}{|c|}{$S$} & \multicolumn{3}{|c|}{$f_{i j}$} \\
\hline & Present & GRASP & $\Delta_{\text {GRASP }}(\%)$ & Present & GRASP & $\Delta_{\text {GRASP }}(\%)$ \\
\hline$\overline{2-1}$ & 0.067234 & 0.066430 & 1.20 & $2.641 \mathrm{E}-02$ & $2.610 \mathrm{E}-02$ & 1.17 \\
\hline $3-1$ & 0.134921 & 0.133900 & 0.76 & $5.818 \mathrm{E}-02$ & $5.772 \mathrm{E}-02$ & 0.79 \\
\hline $4-2$ & 0.003014 & 0.003309 & 9.79 & $1.793 \mathrm{E}-02$ & $1.968 \mathrm{E}-02$ & 9.76 \\
\hline $4-3$ & 0.006490 & 0.006869 & 5.84 & $1.919 \mathrm{E}-02$ & $2.029 \mathrm{E}-02$ & 5.73 \\
\hline $5-1$ & 0.018447 & 0.018690 & 1.32 & $1.190 \mathrm{E}-01$ & $1.205 \mathrm{E}-01$ & 1.26 \\
\hline $5-4$ & 0.411389 & 0.409700 & 0.41 & $4.474 \mathrm{E}-02$ & $4.426 \mathrm{E}-02$ & 1.07 \\
\hline $6-1$ & 0.036441 & 0.036530 & 0.24 & $2.356 \mathrm{E}-01$ & $2.360 \mathrm{E}-01$ & 0.17 \\
\hline $6-4$ & 0.822315 & 0.823300 & 0.12 & $9.863 \mathrm{E}-02$ & $9.855 \mathrm{E}-02$ & 0.08 \\
\hline $7-2$ & 0.109613 & 0.110500 & 0.81 & $6.700 \mathrm{E}-01$ & $6.749 \mathrm{E}-01$ & 0.73 \\
\hline $7-3$ & 0.022235 & 0.022380 & 0.65 & $6.753 \mathrm{E}-02$ & $6.790 \mathrm{E}-02$ & 0.55 \\
\hline $7-5$ & 0.532594 & 0.529100 & 0.66 & $2.794 \mathrm{E}-02$ & $2.731 \mathrm{E}-02$ & 2.25 \\
\hline $7-6$ & 0.106206 & 0.105700 & 0.48 & $2.190 \mathrm{E}-03$ & $2.110 \mathrm{E}-03$ & 3.65 \\
\hline $8-3$ & 0.200116 & 0.201100 & 0.49 & $6.081 \mathrm{E}-01$ & $6.104 \mathrm{E}-01$ & 0.38 \\
\hline $8-6$ & 0.955857 & 0.953300 & 0.27 & $2.143 \mathrm{E}-02$ & $2.075 \mathrm{E}-02$ & 3.17 \\
\hline $9-2$ & 0.000562 & 0.000594 & 5.69 & $4.570 \mathrm{E}-03$ & $4.824 \mathrm{E}-03$ & 5.56 \\
\hline $9-3$ & 0.001079 & 0.001210 & 12.14 & $4.360 \mathrm{E}-03$ & $4.889 \mathrm{E}-03$ & 12.13 \\
\hline $9-5$ & 0.022417 & 0.020760 & 7.39 & $4.625 \mathrm{E}-02$ & $4.283 \mathrm{E}-02$ & 7.39 \\
\hline $9-6$ & 0.044880 & 0.043020 & 4.14 & $4.605 \mathrm{E}-02$ & $4.413 \mathrm{E}-02$ & 4.17 \\
\hline
\end{tabular}


Table 4. Present quantum Stark widths $W$ for ten Ar XVI lines at electron density $N=10^{20} \mathrm{~cm}^{-3}$ for different temperatures, the wavelengths $\lambda$ are taken from the SUPERSTRUCTURE (SST) code of Eissner et al. (1974).

\begin{tabular}{|c|c|c|c|c|c|}
\hline Transition & $T\left(10^{5} \mathrm{~K}\right)$ & $W(\AA)$ & Transition & $T\left(10^{5} \mathrm{~K}\right)$ & $\overline{W(\AA)}$ \\
\hline \multirow{6}{*}{$\begin{array}{c}2 \mathrm{p}{ }^{2} \mathrm{P}^{\circ} 1 / 2-2 \mathrm{~s}^{2} \mathrm{~S}_{1 / 2} \\
\lambda=\begin{array}{c}386.61 \AA \\
2-1\end{array}\end{array}$} & 7.5 & $1.216 \mathrm{E}-02$ & \multirow{6}{*}{$\begin{array}{c}3 \mathrm{p}^{2} \mathrm{P}^{\circ} 3 / 2-2 \mathrm{~s}^{2} \mathrm{~S}_{1 / 2} \\
\lambda=23.50 \AA \\
6-1\end{array}$} & 7.5 & $1.735 \mathrm{E}-04$ \\
\hline & 10 & $1.065 \mathrm{E}-02$ & & 10 & $1.496 \mathrm{E}-04$ \\
\hline & 15 & $8.854 \mathrm{E}-03$ & & 15 & $1.212 \mathrm{E}-04$ \\
\hline & 30 & $6.510 \mathrm{E}-03$ & & 30 & $8.474 \mathrm{E}-05$ \\
\hline & 50 & $5.205 \mathrm{E}-03$ & & 50 & $6.452 \mathrm{E}-05$ \\
\hline & 75 & $4.338 \mathrm{E}-03$ & & 75 & $5.109 \mathrm{E}-05$ \\
\hline \multirow{6}{*}{$\begin{array}{c}2 \mathrm{p}^{2} \mathrm{P}^{\circ} 3 / 2-2 \mathrm{~s}^{2} \mathrm{~S}_{1 / 2} \\
\lambda=352.21 \AA \\
3-1\end{array}$} & 7.5 & $1.002 \mathrm{E}-02$ & \multirow{6}{*}{$\begin{array}{c}3 \mathrm{~d}^{2} \mathrm{D}_{3 / 2}-2 \mathrm{p}{ }^{2} \mathrm{P}^{\circ} 1 / 2 \\
\lambda=24.85 \AA \\
=7-2\end{array}$} & 7.5 & $2.144 \mathrm{E}-03$ \\
\hline & 10 & $8.782 \mathrm{E}-03$ & & 10 & $1.594 \mathrm{E}-03$ \\
\hline & 15 & $7.304 \mathrm{E}-03$ & & 15 & $1.012 \mathrm{E}-03$ \\
\hline & 30 & $5.377 \mathrm{E}-03$ & & 30 & $4.361 \mathrm{E}-04$ \\
\hline & 50 & $4.302 \mathrm{E}-03$ & & 50 & $2.293 \mathrm{E}-04$ \\
\hline & 75 & $3.588 \mathrm{E}-03$ & & 75 & $1.380 \mathrm{E}-04$ \\
\hline \multirow{6}{*}{$\begin{array}{c}3 \mathrm{~s}^{2} \mathrm{~S}_{1 / 2}-2 \mathrm{p}{ }^{2} \mathrm{P}^{\circ} 1 / 2 \\
\lambda=25.52 \AA \\
4-2\end{array}$} & 7.5 & $2.434 \mathrm{E}-04$ & \multirow{6}{*}{$\begin{array}{c}3 \mathrm{~d}^{2} \mathrm{D}_{3 / 2}-2 \mathrm{p}{ }^{2} \mathrm{P}^{\circ} 3 / 2 \\
\lambda=25.01 \AA \\
=7-3\end{array}$} & 7.5 & $1.968 \mathrm{E}-03$ \\
\hline & 10 & $2.098 \mathrm{E}-04$ & & 10 & $1.465 \mathrm{E}-03$ \\
\hline & 15 & $1.697 \mathrm{E}-04$ & & 15 & $9.326 \mathrm{E}-04$ \\
\hline & 30 & $1.170 \mathrm{E}-04$ & & 30 & $4.040 \mathrm{E}-04$ \\
\hline & 50 & $8.832 \mathrm{E}-05$ & & 50 & $2.137 \mathrm{E}-04$ \\
\hline & 75 & $6.996 \mathrm{E}-05$ & & 75 & $1.292 \mathrm{E}-04$ \\
\hline \multirow{6}{*}{$\begin{array}{c}3 \mathrm{~s}^{2} \mathrm{~S}_{1 / 2}-2 \mathrm{p}{ }^{2} \mathrm{P}^{\circ} 3 / 2 \\
\lambda=25.69 \AA \\
4-3\end{array}$} & 7.5 & $2.467 \mathrm{E}-04$ & \multirow{6}{*}{$\begin{array}{c}4 \mathrm{~s}^{2} \mathrm{~S}_{1 / 2}-2 \mathrm{p}{ }^{2} \mathrm{P}^{\circ} 3 / 2 \\
\lambda=18.79 \AA \\
9-3\end{array}$} & 7.5 & $9.741 \mathrm{E}-05$ \\
\hline & 10 & $2.128 \mathrm{E}-04$ & & 10 & $8.428 \mathrm{E}-05$ \\
\hline & 15 & $1.722 \mathrm{E}-04$ & & 15 & $6.858 \mathrm{E}-05$ \\
\hline & 30 & $1.187 \mathrm{E}-04$ & & 30 & $4.807 \mathrm{E}-05$ \\
\hline & 50 & $8.953 \mathrm{E}-05$ & & 50 & 3.697 -05 \\
\hline & 75 & $7.089 \mathrm{E}-05$ & & 75 & $2.996 \mathrm{E}-05$ \\
\hline \multirow{6}{*}{$\begin{array}{c}3 \mathrm{p}^{2} \mathrm{P}^{\circ} 1 / 2-2 \mathrm{~s}^{2} \mathrm{~S}_{1 / 2} \\
\lambda=23.54 \AA \\
5-1\end{array}$} & 7.5 & $1.756 \mathrm{E}-04$ & \multirow{6}{*}{$\begin{array}{c}4 \mathrm{~s}^{2} \mathrm{~S}_{1 / 2}-3 \mathrm{p}^{2} \mathrm{P}^{\circ} 3 / 2 \\
\lambda=74.01 \AA \\
9-6\end{array}$} & 7.5 & $2.940 \mathrm{E}-02$ \\
\hline & 10 & $1.516 \mathrm{E}-04$ & & 10 & $2.412 \mathrm{E}-02$ \\
\hline & 15 & $1.235 \mathrm{E}-04$ & & 15 & $1.735 \mathrm{E}-02$ \\
\hline & 30 & $8.836 \mathrm{E}-05$ & & 30 & $8.672 \mathrm{E}-03$ \\
\hline & 50 & $6.704 \mathrm{E}-05$ & & 50 & $4.831 \mathrm{E}-03$ \\
\hline & 75 & $5.245 \mathrm{E}-05$ & & 75 & $2.969 \mathrm{E}-03$ \\
\hline
\end{tabular}

inverse of collisional line width, which can be roughly expressed as equal to $N_{e} v_{t y p} \rho_{t y p}^{2}$. Thus, the validity condition of the impact approximation can be written as $\rho_{t y p} \ll N_{e}^{-1 / 3} . \rho_{\text {typ }}^{3}$ is called the 'collision volume' that must be smaller than the volume of perturber $N_{e}^{-1}$. The condition of the impact approximation can be written in terms of temperature and the orbital momentum of the perturber. The classical angular momentum $L=\rho m v$ can be related to the eigenvalues of the corresponding quantum-mechanical operator $\mathbf{L}^{2}$ by $L^{2}=(\rho m v)^{2}=\hbar^{2} l(l+1) \Longrightarrow \rho^{2}=\frac{\hbar^{2} l(l+1)}{(m v)^{2}}$, using that $E=\frac{1}{2} m v^{2}=\frac{3}{2} k_{B} T$, we find $\rho_{t y p}=\frac{\hbar l_{t y p}}{\sqrt{m k_{B} T_{t y p}}} \approx 3 \times 10^{-10} \mathrm{~m}$. We use $T_{t y p}=7.5 \times 10^{6}$, and with $N_{e}=10^{20} \mathrm{~cm}^{-3}$, we see that $\rho_{t y p} \ll N_{e}^{-1 / 3}=10^{-6.67} \mathrm{~m}$. There are no other results in the literature to compare with the present Stark width calculations. The good agreement found between our atomic data and other results shows that our line broadening calculations have acceptable accuracy. Other experimental or theoretical results of Ar XVI line broadening would be very helpful to confirm our calculations. 


\section{Conclusions}

In the present paper, we have performed quantum Stark broadening calculations for $10 \mathrm{Ar}$ XVI lines for the range of electron temperatures form $7.5 \times 10^{5}$ to $7.5 \times$ $10^{6} \mathrm{~K}$ and an electron density of $N_{e}=10^{20} \mathrm{~cm}^{-3}$. Six configurations have been used in our calculations. The present structural and radiative parameters have been calculated using the UCL (SST/DW/JAJOM) codes. These parameters have been used in our line broadening calculations. To the best of our knowledge, there are no other results for the Stark broadening in the literature to compare with them. New calculations or measurements of line widths for this ion may be interesting for checking our calculations.

\section{References}

Aggarwal, K. M. \& Keenan, F. P., Energy levels, radiative rates, and electron impact excitation rates for transitions in Li-like ions with $12 \leq Z \leq 20$. 2013, At. Data Nucl. Data Tables, 99, 156, DOI: doi:10.1016/j.adt.2012.03.001

Aloui, R., Elabidi, H., Hamdi, R., \& Sahal-Bréchot, S., Quantum Stark broadening data for Ar VIII and Ar IX lines. 2019, Mon. Not. R. Astron. Soc., 484, 4801, DOI: https://doi.org/10.1093/mnras/stz303

Aloui, R., Elabidi, H., Sahal-Bréchot, S., \& Dimitrijević, M. S., Quantum and Semiclassical Stark Widths for Ar VII Spectral Lines. 2018, Atoms, 6, 20, DOI: https://doi.org/10.3390/atoms6020020

Badnell, N. R., On the effects of the two-body non-fine-structure operators of the Breit - Pauli Hamiltonian. 1997, J. Phys. B: At., Mol. Opt. Phys., 30, 1, DOI: https://doi.org/10.1088/0953-4075/30/1/005

Baranger, M., General Impact Theory of Pressure Broadening. 1958, Phys. Rev., 112, 855, DOI: DOI:https://doi.org/10.1103/PhysRev.112.855

Bethe, H. A. \& Salpeter, E. E. 1957, Quantum Mechanics of One- and TwoElectron Atoms

Dere, K. P., Landi, E., Young, P. R., \& Del Zanna, G., CHIANTIAn Atomic Database for Emission Lines. IV. Extension to XRay Wavelengths. 2001, Astrophys. J., Suppl., 134, 331, DOI: https://doi.org/10.1086/320854

Dimitrijević, M. S., Stark Broadening in Astrophysics (Applications of Belegrade Scool Results and Collaboration With Former Soviet Republics). 2003, Astron. Astrophys. Trans., 22, 389, DOI: 10.1080/1055679031000108167

Djurović, S., Mar, S., Peláez, R. J., \& Aparicio, J. A., Stark broadening of ultraviolet Ar III spectral lines. 2011, Mon. Not. R. Astron. Soc., 414, 1389, DOI: https://doi.org/10.1111/j.1365-2966.2011.18470.x 
Dyall, K. G., Grant, I. P., Johnson, C. T., Parpia, F. A., \& Plummer, E. P., GRASP: A general-purpose relativistic atomic structure program. 1989, Comput. Phys. Commun., 55, 425, DOI: doi:10.1016/0010-4655(89)90136-7

Eissner, W., The UCL distored wave code. 1998, Comput. Phys. Commun., 114, 295, DOI: https://doi.org/10.1016/S0010-4655(98)00082-4

Eissner, W., Jones, M., \& Nussbaumer, H. J., Techniques for the calculation of atomic structure and radiative data including relativistic corrections. 1974, Comput. Phys. Commun., 8, 270, DOI: https://doi.org/10.1016/00104655(74)90019-8

Elabidi, H., Ben Nessib, N., Cornille, M., Dubau, J., \& Sahal-Bréchot, S., Electron impact broadening of spectral lines in Be-like ions: quantum calculations. 2008, J. Phys. B: At. Mol. Opt. Phys., 41, 025702, DOI: 10.1088/09534075/41/2/025702

Elabidi, H., Ben Nessib, N., \& Sahal-Bréchot, s., Quantum mechanichal calculations of the electron-impact broadening of spectral lines for intermediate coupling. 2004, J. Phys. B: At. Mol. Opt. Phys., 37, 63, DOI: doi:10.1088/09534075/37/1/004.

Elabidi, H. \& Sahal-Bréchot, S., Quantum mechanical Stark widths for Ar V and Ar VI lines: scaling with temperature. 2018, Mon. Not. R. Astron. Soc., 480, 697, DOI: 10.1093/mnras/sty1858.

Elabidi, H., Sahal-Bréchot, S., \& Dimitrijević, M. S., Quantum Stark broadening of Ar XV lines. Strong collision and quadrupolar potential contributions. 2014, Adv. Space Res., 54, 1184, DOI: doi:10.1016/j.asr.2013.08.017

Hibbert, A., CIV3 A general program to calculate configuration interaction wave functions and electric-dipole oscillator strengths. 1975, Comput. Phys. Commun, 9, 141, DOI: 10.1016/0010-4655(75)90103-4

Kramida, A., Ralchenko, Y., Reader, J., \& NIST ASD Team. 2018, NIST Atomic Spectra Database (ver. 5.5.6), [Online]. Available: https://physics.nist.gov/asd [2018, July 25]

Lemen, J. R., Sylwester, J., \& Bentley, R. D., Determination of the calcium elemental abundance for 43 flares from SMM-XRP solar X-ray spectra. 1986, Adv. Space Res., 6, 245, DOI: doi:10.1016/0273-1177(86)90153-5

McKeown, K., Aggarwal, K. M., Keenan, F. P., \& Rose, S. J., Energy levels and radiative rates for Li-like Ar XVI and Fe XXIV. 2004, Phys. Scr., 70, 295, DOI: https://doi.org/10.1088/0031-8949/70/5/006

Peacock, N. J., Barnsley, R., Coffey, I. H., et al., X-ray spectroscopic diagnostics of core ion confinement in large (JET) and medium size (COMPASS) tokamaks. 1997, Fusion Eng. Des., 34, 171, DOI: 10.1016/s0920-3796(96)00633-3 
Saraph, H. E., Fine structure cross sections from reactance matrices-a more versatile development of the program jajom. 1978, Comput. Phys. Commun., 15, 247, DOI: 10.1016/0010-4655(78)90095-4

Whiteford, A. D., Badnell, N. R., Ballance, C. P., Loch, S. D. O'Mullane, M. G., \& Summers, H. P., Excitation of $\mathrm{Ar}^{15+}$ and $\mathrm{Fe}^{23+}$ for diagnostic application to fusion and astrophysical plasmas. 2002, J. Phys. B: At., Mol. Opt. Phys., 35, 3729, DOI: 10.1088/0953-4075/35/17/309 